\title{
Coupling Culture and Medicine in Chile
}

\author{
Kaitlin Endres ${ }^{1}$, Mitchell Nicholls² \\ ${ }^{1}$ Faculty of Medicine, University of Ottawa, Ontario, Canada \\ ${ }^{2}$ Faculty of Medicine, University of Western Ontario, Ontario, Canada
}

\author{
ABSTRACT
}

This elective report provides an overview of a month-long Internal Medicine elective in Coronel, Chile, completed by a first-year medical student from Ottawa and a second-year medical student from Western in July 2018. As a couple, we had the opportunity to apply to the International Federation of Medical Students Association (IFMSA) together in order to complete our international exchange in the same city. While in Chile, we had the opportunity to shadow many subspecialties, learn how one becomes a physician in South America, and gain exposure to Chilean culture and traditions from our host family. Our experience was unique in that it allowed us to learn about medicine and Chilean patient populations within our assigned hospital, but also from the family members we visited who work as Chilean physicians.

RÉSUMÉ

Ce rapport de stage donne un survol d'un stage en médecine interne pendant un mois à Coronel, Chili, complété par un étudiant de médecine en première année d'Ottawa et par un étudiant en deuxième année de Western, en juillet 2018. Comme couple, on a eu la chance de faire demande ensemble à travers de la Fédération internationale des associations d'étudiants en médecine (IFMSA) afin de compléter notre échange international dans la même ville. Au Chili, on a eu l'occasion de suivre plusieurs sous-spécialités, d'apprendre comment devenir médecin à l'Amérique du Sud, et de gagner une expérience unique aux cultures et traditions chiliennes de notre famille hôte. Notre expérience a été unique, car elle nous a permis d'apprendre à propos de la médecine et la population de patients chiliens à notre hôpital assigné, ainsi qu'avec les membres de famille qu'on a visitée qui travaillent comme médecins au Chili.

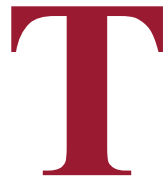

his past summer, we travelled to Chile for a onemonth elective in Internal Medicine (IM). Each of us had particular reasons for selecting Chile as an elective choice. For Kaitlin, she was interested in understanding more about Mitch's background and the country his family was from. For Mitch, he was interested in experiencing medicine in a country he had visited often since his childhood. We were placed in Coronel, a small mining town near Concepcion. There were lots of ups and downs, difficult situations, and new experiences over our four weeks, and now that we are back in Canada, we have had time to think about our experiences. These are some of our thoughts, tips, and reflections in hopes that they may provide some insight into our elective experiences and stimulate questions to further investigate for those contemplating participation in an international elective.

Doing an elective in a country where you do not speak the language always leads to some unease (1). While Chile is a Spanish speaking country, we were assured that our instruction would be in English. We arrived on our first day to our host family, who spoke only Spanish. We were out of our element from the beginning and had to improvise in order to communicate. Simple things, like how the shower worked, when dinner was or what areas of town were safe to explore became difficult conversations due to the language barrier. A good translator app certainly went a long way.

Our first day in the hospital proved to be even more difficult due to communication issues. We had been given some orientation materials via email from the student coordinators for the exchange, but nothing more. We had the name of the doctor but no directions or a place to meet. We arrived at the hospital to discover there were not room numbers, a directory, or clear areas for different departments. After locating our attending physician, he gave an impassioned speech to us (along with two other exchange students) and set off to the wards to show us how things were done. At least that is what we believe happened, as everything was in Spanish.

We completed our elective alongside a cohort of Chilean medical students from nearby Concepcion. Days on which

Keywords: International Elective; Chile; Internal Medicine; Culture 
Chilean medical students were present were straightforward and educational. They made sure we were understanding various patient presentations, showed us unique findings on patients' physicals and translated the doctors' instructions into English. One thing we overlooked was that it was Chilean winter and the students had their break in the middle of our time there. More than half of our time in the hospital was completed without these medical students to guide us. Many days, we would show up to the IM ward only for the doctor to ask why we "had not gone home yet?" or "oh, you are back?". When we think about the situation now, it makes a lot more sense. It would be like seeing exchange students in the hospital on Christmas break, when all the local medical students had gone home. While at first discouraging, the days where there was little work to be done on the IM wards ultimately provided us with the opportunity to shadow other areas of the hospital including the Emergency Department and Surgical Operating Room (OR).

Observing surgeries in Chile was quite similar to our previous experiences in Canadian ORs. The sterile procedure was identical, as was the role of the scrub nurses and medical students in the OR. Often, there was also an anesthesiology nurse to support the anesthesiologist which was unique. It was quite rare during our time in Chile for us to see a patient under general anesthetic, as most patients were instead placed under spinal anesthesia. Surgeries moved much faster in Chile than in Canada with few breaks in-between patients, often coming at the expense of patient privacy. For example, doors to ORs were open at all times, allowing healthcare professionals not involved in the patient's direct care to see the patient being draped and sterilized. In Canada, patient autonomy is placed at the forefront of care, and the breaks between each OR case allow time to prevent these breaches in patient confidentiality. Further, with no central heating in Chile, ORs were kept at the necessary temperature through electric heaters. If you were worried about fainting in a Canadian OR, you had better hope you were not stuck beside the heater in a Chilean OR, scrubbed in and hoping for the compression socks to keep you upright long enough for the surgery to end.

In the 1970s, the small town of Coronel where our hospital was located was a booming city with a rich mining industry. The mines have since closed, and Coronel is now one of the poorest cities in Chile (2). Our hospital faced extremely high rates of respiratory disease, and Coronel is referred to anecdotally by physicians in South America as the "tuberculosis capital" of
Chile. According to our preceptor, every internist at our hospital had been treated for tuberculosis at least once throughout their career. As a whole, Chile does not have a tuberculosis epidemic, but the Coronel region does (3). When planning an elective, remember that research on the whole country will not necessarily identify localized health crises. We arrived without our own N95 masks only to realize that in Coronel, this piece of equipment would be key in protecting ourselves from respiratory illnesses like tuberculosis. If a patient in Coronel was given a mask to prevent the spread of their tuberculosis, the mask was often re-used for many days until it was no longer tight on the patient's face. Infection control measures were ignored in Coronel, not due to ignorance, but rather due to cost.

The hospital in Coronel also operated "Poly-Clinics" which functioned similar to a walk-in where patients could come in and see whichever doctor was on-call for clinic that day. Within these clinics, there were often many learners, plus a doctor seeing the patient. It definitely came as a shock to see patients so open to the high number of learners in the room. For the first little while, we would always ask the other medical students and/or doctors to introduce us to the patient and obtain consent. We quickly learned that Chilean patients were more than used to being examined by multiple different learners without introduction. We were often sent off to complete physicals without any means of translating our intentions to the patients, yet patients would lift their gown so we could check their legs for peripheral edema after listening to their heart sounds, even without prompting. It seemed strange and unfair for the patient to be examined so many times in a row, but no patient seemed to mind. They actually seemed very appreciative of the multiple opinions a medical team could provide in just one short visit.

Finally, we had the opportunity to visit Mitch's family in Chile. His dad was born in Chile, and many of his cousins still live there. His grandfather worked for the Chilean government in the Ministry of Health. When General Pinochet overthrew the government in 1973 and began to persecute government workers and their families, many feared for their lives and fled the country (4). This trip served as an opportunity for both of us to learn more about this history and to spend time with these family members. Many of them still work in healthcare and we were able to discuss the differences between our healthcare systems. Although many of our experiences in Coronel led us to believe that Chilean healthcare was quite different from 
Canadian healthcare, our conversations with Mitch's family made us realize things were really quite comparable. In larger centers, like Santiago, where Mitch's family is from, healthcare is extraordinarily similar. Hospitals function identically, with many departments, consulting services, and state of the art equipment. What this highlighted more than anything was the disparity in healthcare quality depending on location. This made us think of the similar issues Canada faces. In our nation's Indigenous communities, we lack in many aspects of healthcare including access to specialists or gold standard diagnostic testing, much like Coronel (5). Our experiences reminded us that the issues we face here in Canada are universal.

Overall, our elective in Chile was an eye-opening experience, but not in the ways one might expect. In the Chilean healthcare system, paternalistic practice remains common in stark contrast to the beneficence principles we strive to uphold here in Canada. There are clear disparities in the quality of healthcare based on location. However, Chile also practices modern, evidence-based medicine with state-of-theart technology. It is a medical system in flux, and it highlights many of the issues we see in our own medical system as well. Moreover, it left us both interested to return to see how the healthcare system continues to develop and to see more of the beautiful landscape the country is famous for.

\section{REFERENCES}

1. Hurley K. Another language-Problem or opportunity? The Electives Network; 2011 Nov 29; [cited 2019 Mar 30]. Available from: https://www. electives.net/blog/post/2011/11/29/another-language-problem-oropportunity

2. Palma, G. Trying to 'Tax and Spend' Oneself out of the 'Dutch Disease': The Chilean Economy from the War of the Pacific to the Great Depression. An Economic History of Twentieth-Century Latin America. St Antony's Series. Palgrave Macmillan, London. 2000. 217-240 p.

3. World Health Organization. Global Tuberculosis Report 2018 [Internet]. WHO; 2018 [cited 2019 Apr 01]. Available from: https://www.who.int/tb/ publications/global report/en/

4. Packenham RA and Ratliff W. What Pinochet Did for Chile [Internet] Stanford (CA): Stanford University, Hoover Digest: Research + Opinion on Public Policy; 2007 Jan 30; [cited 2019 Apr 03]. Available from: https:// www.hoover.org/research/what-pinochet-did-chile

5. Talaga T. The health system in Canada's North is failing - but not by accident. 'It is designed to do what it is doing' [Internet]. The Toronto Star; 2018 [cited 2019 Mar 30]. Available from: https://www.thestar.com/ news/atkinsonseries/2018/10/19/the-health-system-in-canadas-north-isfailing-but-not-by-accident-it-is-designed-to-do-what-it-is-doing.html 